QUADERNS DE FILOSOFIA VOL. VI NÚM. 2 (20I9): 27-4I

eISSN: $234 \mathrm{I}-3042$ DOI: I O.7203/QFIA. 6.2.I 6053

JAIME Soler PARRA

$U N E D$

\title{
Defining life as a non-essentialist natural kind
}

Received: 15/7/19. Accepted: 31/7/19

Abstract: The increasing number of proposals to define the concept of life in biology has led some authors to consider this task useless and without sense. All sceptics base their argument on the idea that life is a natural kind with a strong metaphysical commitment. Considering this, the aim of this paper is to explore the concept of life as a non-essentialist natural kind. It is intended to highlight that complex scientific concepts are better understood from points of view that are not constrained by the rigid frameworks of essentialism and the realism/conventionalism dichotomy.

Keywords: natural kind, definition of life, essentialism, operational definitions.

\section{INTRODUCTION}

T N I 976 two landers, part of the Viking program, touched down the Martian surface. One of its goals was to find indications of biological activity on the red planet, for which they had a series of experiments aimed at finding such signs. The interpretation of the results was quite complex, although at first they were considered negatively. Since then, the development of astrobiology and other new biological disciplines has been constantly increasing. As a result, some doubts about how to interpret the Viking experiments and other similar researches have emerged. To the extent that astrobiology and other new disciplines move within the limits of traditional biology, it is understandable that the interest in defining the concept of life has increased.

In this sense, Trifonov (201 I) and Diéguez (2013) take as reference the work of Popa (2004), who collects almost one hundred different proposals of 
the concept of life. It is also interesting to notice that one third of the proposals correspond to the year 2002, the last considered by Popa. Therefore, to get an idea of the complete picture, we must add the proposals that have emerged since 2002. Simply as a sample, point out the contributions of Gánti (2003), Ruiz-Mirazo, Peretó and Moreno (2004), Benner (2010), Damiano and Luisi (2010), Tsokolov (2010), Trifonov (20 I I), Diéguez (2008; 2013), Razeto-Barry and Ramos-Jiliberto (2013), Luisi (2015), Hermida (2016), Ferreira and Umerez (2018), or Smith (20 I 8). The number of different proposals, as can be seen, far exceeds one hundred.

Of course, it is possible to consider this huge quantity of proposals in a more limited number of types of definitions. One well-known classification was proposed by Sagan (1970), who considers physiological, metabolic, biochemical, genetic and thermodynamic definitions. More recently, authors such as Tirard, Morange and Lazcano (2010), as well as Smith (2018), have classified definitions of life as thermodynamic definitions, self-regulation definitions, and evolutionary ones.

On the other hand, new approaches (e.g. hybrid theories, analysis of life vocabulary) try to overcome the difficulties derived from the large number of proposals. But neither analysis of life vocabulary nor hybrid proposals elicit a sufficient consensus. Regarding the former, there are some important objections to their basic thesis ${ }^{1}$. Perhaps one of the most promising ways of research are hybrid proposals, which consider different types of properties related through complex phenomena. Nevertheless, as Ruiz-Mirazo, Peretó and Moreno (2002) show, hybrid theories are still far from solving may of the relevant questions regarding what life is.

Precisely, it is the large number of different proposals, and the difficulty to find a minimum denominator among them, which has favoured the scepticism of some authors. In relation to the difficulty to find an essential property of the concept of life, other questions related to the concept of life remain unresolved: the diffuse boundary between living and non-living entities (DuPRÉ and O'MALLEY 2009), the different assumptions of distinct disciplines (Ruiz Mirazo, Peretó and Moreno 2004; Machery 20 i2), the complexity of the processes involved (Popa 2004), or our limited knowledge about different types of life (CLELAND 2002).

Of course, scepticism is not always expressed in the same way. For instance, some authors conclude that life is a human kind (KeLler 2002), whereas other consider life as an individual (Mariscal and Doolittle 20 i 8). Howothers.

${ }^{1}$ See the criticism by Popa (2012) or Bor Luen Tan (2012), to Trifonov (20II), among 
ever, all sceptics share a common idea, that is, to define life is to find a basic essential property (or a set of essential properties). But is it possible to define life considering a different way? In this vein, some authors as Diéguez (2008; 20I3), and more recently Ferreira and Umerez (20I8), have explored some alternatives based on the ideas of homeostatic kinds and relevant stability.

Bearing this in mind, the first goal is to show that criticisms to define of life expressed by Keller, Cleland and Chyba and other authors are valid only for essentialist definitions, that is, they assume that to define life is to consider it as essentialist natural kind (section 2). Secondly, to show that researchers, in their practices, do not use essentialist definitions, but operational ones (section 3). In section 4, life will be considered as a non-essentialist natural kind, pointing out different ways in which this can be done. For this, different types of theories (Diéguez, Ferreira and Umerez, Dupré) will be considered. Finally, it is intended to highlight that complex scientific concepts are better understood from points of view that are not constrained by the rigid frameworks of essentialist natural kinds and the realism/conventionalism dichotomy (Putnam, 1988). It will also show to what extent this limitation could be overcome by non-essentialist proposals.

\section{ObJections to the POSSIBILITY OF DEFINING THE CONCEPT OF LIFE}

As noted above, nowadays skepticism about the possibility of defining life is increasing. Although not all skeptics share the same argument, all share the criticism regarding the possibility of defining life as a natural kind in a strong metaphysical sense. But research is far from finding an essential property to define life (or some essential properties). Without these properties, the kind has no clear limits, so it is only possible to delimit it in a conventional sense.

Thus, the large number of definitions about the concept of life is the result of a wrong metaphysic commitment. The issue has no solution, because life is not a natural kind, but other type of entity (an individual or a conventional kind). It is possible to find these or similar ideas in Keller (2002), Tirard, Morange and Lazcano (2010), Machery (2012), Cleland (2002; 20II) and Mariscal and Doolittle (2018).

According to Keller (2002), it is possible to define life, but only in a conventional sense. Keller suggests that the demarcation between life and nonlife is an historical and cultural issue. In fact, before the nineteenth century, the opposite of living was not inorganic, but dead. Keller considers that the current situation with respect to definitions shows that life is not a natural kind, but a conventional one. Thus, it is defined by the interests and values 
of human beings, and this also explains why there is no minimum consensus on necessary properties. To define life becomes an historical and social issue, rather than a scientific one.

Tirard, Morange and Lazcano (20 10) try to move the focus of attention. If defining the concept of life has not yielded fruitful results, it may be more interesting to shift the question to how the associated characteristics of life are acquired. This means treating life as an empirical and historical concept. So it is only possible to consider the concept of life within a conceptual framework, rather than by a precise definition.

Machery (2010) is also critical of the possibility of defining the concept of life. From his point of view, life can be understood as a folk concept or as a scientific concept. Modern research on folk concepts does not consider them as definitions, so if life were a folk concept, it would not be definable. Therefore, to be definable it should be considered as a scientific concept. It is possible to do this, and in fact different disciplines use distinct definitions. The problem is that each discipline considers the concept of life in a different way. If they do not agree on what is the essential property (or properties) of life, a general definition cannot be found. So to define life is not possible (considering folk concepts) or it is pointless (as a scientific concept).

Cleland (2012) expresses its reluctance considering different objections. The first is the confusion between linguistic entities and the epistemic ones. Thus, definitions refer to the way that speakers use terms, that is, to define is a linguistic issue. But when scientists use the concept life, they are interested in what really life is, not how speakers use this term. From a rather exhaustive study of the theories of reference, Cleland assumes the position defended by semantic externalism. This leads her to defend that concepts as water (and life) are not stipulations. In addition, Cleland considers that definitions of these type of concepts can only make sense within a broader theoretical framework. Therefore, concepts such as water, only has sense in a more general molecular theory. Similarly, the concept of life only makes sense within a more general theoretical context about biology.

A second criticism considers our limitations on the knowledge of different types of life. If as it seems according to different theories, all current organisms are descended from a common ancestor (LUCA), then we only know one type of life. Defining a kind from only one example results, at the very least, risky. The situation is similar to define mammals by only knowing zebras. Although stripes are common to all of them, the presence of mammary glands is much more determinant, even if only one half of the individuals possesses them.

Finally, Mariscal and Doolittle (2018), in a recent paper, consider life in as an individual. This idea is not new, and some authors has considered life on 
Earth as an individual (for instance, Hermida 20I6). But according to Hermida, life on Earth can be understood as an instance of a more general kind, whereas Mariscal and Doolittle reject this idea. According to them, every type of life is an individual, so it would be more accurate to say that each type of life is Life, with capital letters. It could be possible to find some common properties in different Lifes (for instance, among life in different planets, or between Life on Earth and synthetic Life). But such groupings respond to the epistemic needs of researchers, not to any ontological priority.

As can be seen, criticisms and arguments to reject a possible definition are very different in distinct authors. But all of them assume that to define life is to consider it as an essentialist natural kind. According with this idea, natural kinds are associated with a(some) necessary(ies) and sufficient property(ies). The intense debates about whether what defines life is the capacity to evolve, to selfregulate or both respond to the need to find such properties. There is a strong metaphysical commitment, so natural kinds are real and independent of human beings. Usually that independence is ensured through causal mechanisms.

On the other hand, according to this essentialist view, the demarcation of natural kinds is given by properties univocally considered, so there are no intermediate cases between the living and the non-living. A paradigmatic example of this is the definition of life as an autopoietic system given by Maturana and Varela (1973), especially in its first formulations. In this case, the systems are autopoietic or not, but it does not make sense to consider partially autopoietic systems.

As a consequence, to define life in an essentialist sense is to fix the concept one for all, according to some properties independent from human beings. So according to this view, we need more research in order to find the basic essences of life. Nevertheless, as critical authors highlight, it is difficult to defend that life is a natural kind if it must satisfy these strict requirements. So their criticisms works well considering natural kinds in this strong metaphysical sense. However, this debate can be considered from a different perspective, that is, asking if essentialist definitions are really used by scientists, or not. It is also interesting to ask whether these criticisms are valid for other ways of understanding natural kinds.

\section{USEFULNESS OF DEFINING THE CONCEPT OF LIFE}

In the previous section it has explained that criticisms about the possibility to define life work well considering definitions as essentialist natural kinds. But as Bich and Green (2017) show, scientists use definitions in an 
instrumental, open and flexible way. They call these definitions "operational definitions". Nevertheless, it is justified to ask what is the real way used by researchers to define life. In this section, it will be explained why the benefits of using instrumental definitions of life in a non-essentialist way may be greater than their risks.

As Bich and Green show, definitions can guide research through feedback processes. Scientists use definitions in an instrumental sense, starting with provisional theoretical definitions. Those definitions are used in order to guide research and design experiments according to them. The results of these experiments are used to reconsider the original definition, and change it if necessary, "definitions are exploratory tools that can change over time and across research programs" (14). Then this feedback process starts again. Bich and Green show this process through Luisi's research.

Luisi (1998) started his research with an autopoietic conception of life. This first definition served as a guide for its subsequent research, in an open and revisable way. Based on this theoretical model, Luisi and his team designed experiments that improved the understanding of different aspects of cell membranes, not well-known until that moment. As a result, they introduced changes in the theoretical model, allowing the development of new lines of research. For example, in 2006 and 2009 Luisi explicitly included references to the medium in his definition of life. On the other hand, since 2006 Luisi and his team seem to consider the limit of life in a non-essentialist sense, at least in the context of minimal cells, "clearly, the term minimal cell depicts large families of possibilities and not simply one particular construct" (272). Both modifications change significantly the original definition, and cannot be understood in the context of essentialist definitions.

Moreover, not defining concepts could be problematic. The research carried out by the Viking program show this clearly, due to the absence of a scientific definition of life. As Benner (2010) shows, there were experiments with both negative and positive results, but the final conclusion was negative. It seems clear that in this case the negative evidence had a greater weight. Such conclusion was linked to certain unspecified assumptions, namely, that life must be understood as life-on-Earth, at least in a metabolic sense. As those assumptions were not explicitly specified, researchers tried to respond to the conflicting results reinterpreting the positive ones. Of course, there was another possibility, that is, not to reinterpret the result, but assumptions about life. However, this only has sense if those assumptions, that is, the definition of life considered, is explicitly formulated.

This shows an important aspect. Even when explicit definitions are not formulated, researchers have certain beliefs about the concepts they work with. 
Some questions arise if definitions are assumed implicitly. How to properly assess a concept if it is not defined? According to what criteria? It is possible to change an implicit definition considering empirical research? If were possible, how to do this? As it happened in Viking experiments, not having explicit definitions could lead researchers to confusing, even mistaken, situations.

Defining the concept of life is also relevant in order to delimit the fields of research, and thus, the possible pertinent investigations in different disciplines. In the research on the origin of life on Earth, it seems obvious to take as a starting assumption that life is based on carbon, and the presence of water is essential for life (on the possibility of alternative forms of life on Earth, see Cleland and Copley 2005). However, in other disciplines such as astrobiology, it is not only possible, but even pertinent, to explore other options.

To see this, it is interesting to show some theories about these alternative options. Beyond the debate on whether or not life can be based on other material components such as silicon, authors such as Benner, Alonso and Carrigan (2004) explain how ammonia could play a water-like role, "metabolism in liquid ammonia is easily conceivable" (170). In the same vein, sulfuric acid can be a suitable solvent for life processes "sulfuric acid is a reasonably good solvent that supports chemical reactivity" (171). Of course, other authors like Pace (200I) believe that life beyond Earth must be materially similar to life on it. On the other hand, as Lange (I996) and other authors show, in artificial life it is common to consider the concept of life without a specific material support. Although this idea is especially popular in artificial life, it is possible to find it in other disciplines, as Popa (2004) shows.

The previous examples show how different disciplines use distinct assumptions regarding the concept of life. As already explained in the previous section, this has been criticized by Machery, who concludes that worrying about the concept of life is something pointless. However, far from it, here it is defended that defining the concept of life is useful both positively and negatively. Positively because definitions can guide scientific research in an open and feedback way, and according to new discoveries. Negatively, because as the example of the Vicking program shows, if the concepts used are not sufficiently defined, research could lead to confusing results.

\section{LIFE AS A NON-ESSENTIALIST NATURAL KIND CONCEPT}

At this point, it seems clear that it is difficult to define life as natural kind in a strong metaphysical sense. On the other hand, it is useful to define this concept. Bearing this in mind, how to reconcile both ideas? 
The solution can be found considering other types of natural kinds. As other debates in biology, such as species, there are other ways of considering natural kinds. The first of these possibilities was explored by Diéguez (2008; 2013), who shows that it is possible to consider life as a homeostatic natural kind. According to this concept, the presence of one or more properties favours the presence of other properties of the kind (due to causal mechanisms), but not in a necessary sense. Thus, it is not necessary for an individual to share all the properties of the kind.

According to Diéguez, life understood as a homeostatic property cluster is characterized by satisfying part of the properties of the kind favours the presence of other properties, but not necessarily. As a result, in absence of a set of necessary properties, the demands from a metaphysical point of view are lower than in the case of traditional essentialism. In second place, causal mechanisms ensure the realism of the proposal, that is, kinds are not a mere convention. Finally, boundaries of life are fuzzy, since it is not necessary for all individuals to satisfy all properties associated with the kind.

Diéguez's proposal is based on the idea of homeostatic property cluster developed by Boyd (1999). Thus, the difficulties that Diéguez must solve are the same ones that Boyd must face. First, according to Khalidi (2013), some causal mechanisms that justify natural kinds do not tend towards equilibrium, so they are not homeostatic. This question is something that must be taken into account in complex concepts, such as life.

Ereshefsky (2010) is more critical. According to this author, Boyd prioritizes the relationship of similarity when establishing homeostatic natural kinds. So those kinds prioritize relations of similarity to historicity (although it is not incompatible with it). However, Ereshefsky considers that there is a priority in evolutionary aspects compared to similarity relations. Therefore, Boyd's theory is inadequate, at least in historical sciences, such as biology.

On the other hand, Craver (2009) expresses his objections based on the way in how the relevant causal mechanisms are selected. As the author shows, the same process can be studied through different causal mechanisms. Such mechanisms are not only different, but sometimes they are also incompatible. According to what criteria can one prioritize versus another? In Craver's opinion, the choice is given by the interests of the researchers, what it means to overcome the metaphysical priority implicit in Boyd's proposal.

Ferreira and Umerez (2018) propose some modifications on the basic homeostatic theory in order to solve their problems. Thus, based on the idea of stability developed by Slater (2015), they modify some of the most problematic aspects, such as the role of mechanisms. To do this, they substitute the mechanisms for the concept of relevant stability. In any case, the problem 
raised by Craver persists, since it is not clear how the relationship between the relevant stability and the epistemic role of scientific practices is articulated. Of course, it is possible to leave the proposal open, although this assumes the vagueness of the proposal.

In order to define life, another possibility is to consider promiscuous naturals kinds. Although this way has not explored to define life, it was used by Dupré (I98I; I 999) and others to define species. Unlike what happens with homeostatic natural kinds, promiscuous kinds have no metaphysical commitments, only epistemic ones. According to these commitments, it is possible to classify the same entities in different ways (crosscutting natural kinds). This allows Dupré to overcome the difficulties pointed out with respect to the homeostatic kinds. And this is because in this case there are no metaphysical commitments articulated through causal mechanisms.

Nevertheless, this proposal should not be confused with conventionalism. The fact that there are multiple ways of classifying reality does not mean that such ways are stipulated. It is interesting to remember that Dupré is declared realistic, although in other promiscuous authors, such as Brigandt (20 I I) this commitment seems more diffuse. On the other hand, promiscuous proposals are interesting from the point of view of complex concepts such as life, insofar as they allow different disciplines to use different criteria, without having to adopt a conventional approach.

However, promiscuous proposals, even showing an interesting way to define the concept of life, must be able to clarify some aspects. One of the most confusing is the criteria that justify the realistic commitment. Although Dupré shows a realistic commitment, it is not clear according to which criteria is declared as such. No, of course, from any metaphysical commitment, which are openly rejected. Without a more precise clarification of this point, this type of proposal may have difficulty distinguishing it from conventionalism, especially in those authors like Dupré who insist on realism as something characteristic of their proposals. Here it is interesting notice that, according to Brigandt, there is a gradation between natural and conventional kinds, that is, there is not a precise limit between them.

\section{IS LIFE A PROMISCUOUS NATURAL KIND?}

At this point, it can be clearly seen that not only essentialist proposals, but also homeostatic ones, have difficulties in giving an account of the concept of life. On the other hand, understanding natural kinds in a promiscuous way offers some advantages. First, promiscuous natural kinds are compatible with 
the diffuse limits of the concept of life. In addition, to the extent that such kinds depend on the interests and values of researchers, it is not necessary to define every kind in exactly the same way, in different disciplines. This allows, for example, to classify cetaceans and fish within the same kind, according to hydrodynamic criteria. A final advantage, perhaps the most interesting, is that promiscuous natural kinds are compatible with the real scientific praxis (remember the cases of Luisi and the Viking program) while other proposals face difficulties in this regard.

It is true that some of these advantages are also found in other nonessentialist proposals (Diéguez and Ferrreira and Umerez). But these proposals have difficulties to justify the objections pointed out by Khalidi, Ereshefsky or Craver, something that does not happen in the case of Dupré, because he does not consider metaphysical justifications. Complex concepts, such as life, do not lend themselves to justifications of this type. Instead, promiscuous proposals allow focusing on scientific practices, making it possible to distinguish those that are successful from those that are not, according to epistemic and axiological criteria. However, this has repercussions on the way of understanding natural kinds.

This leads to an important issue that cannot be overlooked. A good part of the issue comes from accepting the realism/conventionalism dichotomy. This is not place to analyze this problem, rooted in opposing philosophical traditions (Putnam I 988). However, it is important to consider that this problem underlies the debate on how to define the concept of life (and natural kinds in general). Indeed, authors with metaphysical commitment seek to find those mechanisms that ensure that kinds are not a mere conventions, as conventionalists claim.

Something that follows from what has been said so far is that to consider the concept of life within this debate has not helped to solve the issue. That is why here it is proposed to leave this framework. Instead, it is intended to shift the focus of attention towards how researchers use complex scientific concepts, such as life, in line with Bich and Green's (20I7) research. However, unlike such authors, here it is showed that there are non-essentialist ways to understand natural kinds that can be understood operationally.

The main problem of promiscuous theories comes, precisely, from not accepting with all its consequences the epistemic and axiological commitments as opposed to the metaphysical ones. In complex scientific concepts appear a plurality of aspects that cannot be studied from the real / conventional simplification. Instead, it is possible to use promiscuous kinds as tools capable of allowing the development of scientific disciplines, in an open, plural and revisable way. Which is precisely what scientists seem to do in their investigations. 
Following Hacking (2007) and Brigandt (201 I), it is possible to say that the idea of natural kinds has an undesirable metaphysical baggage per se. Natural membership is considered as a human-independent characteristic of natural kinds. This is something explicitly assumed in essentialist natural kinds. However, this idea underlies also homeostatic and promiscuous natural kinds, although more subtly. In fact, this human-independence seems to be, in some sense, before the insistence by Dupré on realism. That is the reason why Brigandt proposal is, perhaps, more interesting than other promiscuous ones. According to him, there is not a precise border between natural and nonnatural kinds, "I do not think that there is any clear-cut metaphysical boundary between natural kinds and other kinds" (175).

Considering this, could be interesting to define life as a promiscuous natural kind? The concept of life is assumed by researchers as an empirical tool, neither in a strong essentialist sense nor in a conventional one. So the dichotomy between realism and conventionalism is not useful in complex concepts, such as life. And is not the way used by researchers to consider the concept of life. Life only can be considered as a natural kind overlooking this dichotomy. This, if possible, only can be done in a promiscuous framework.

As a conclusion, if were possible to consider life as a natural kind, promiscuous natural kinds could be best candidate among the different types of natural kinds. But as can be seen, the metaphysical baggage of the concept of natural kind as is commonly understood contradicts the way in which natural kinds are considered by the most promiscuous authors. Which are, precisely, those that best seem to adjust when defining the concept of life as a natural kind. Perhaps, if were not possible to adjust the concept of natural kind to this weak metaphysical commitment, it could be replaced by a different term. As a proposal, the concept of scientific category could adopt the epistemic characteristics of promiscuous natural kinds without metaphysical commitment. In any case, answering this question is not the target of this paper, and therefore this will be left open for a later discussion.

\section{Conclusions}

Debates on concepts such as species have developed different theories about natural kinds, as homeostatic or promiscuous kinds, among others. Nevertheless, authors who consider life as a natural kind do so from a rather limited perspective. They only consider life as a natural kind in an essentialist sense, with a strong metaphysical commitment. As noted, Diéguez and Ferreira and Umerez are an exception, as they open the debate to new possibilities. In 
addition, there are other alternatives that have not been explored. Considering life as a natural homeostatic property cluster, and specially understanding life as a promiscuous kind, it is possible to overcome the difficulties pointed out by critics.

Behind essentialist proposals lies a problem of greater scope, namely, the way to justify the realism of natural kinds. According to this the debate moves towards how to justify the metaphysical commitments of such kinds. However, considering life in such terms does not seem to solve the issue. This is the reason why some authors choose to defend that life is a conventional concept, or simply propose to abandon its study. Against this, it is intended to highlight that epistemic and axiological aspects are inseparable of complex concepts. For this reason it lacks sense, as is commonly assumed in natural kinds, to establish a line of separation between the real and the conventional aspects.

In scientific practices, researchers use concepts such as life in a much more open way than that proposed by metaphysical essentialism. Proposals are reviewable according to the empirical results, and therefore they are not mere conventions or stipulations. That is why taking into account the way in which complex concepts such as life are defined can be useful in the development of research. Among the possible options, promiscuous theories are characterized to focus on epistemic and axiological aspects against metaphysical and realistic commitments.

So it is possible to define life as a promiscuous kind, and it could be interesting for researchers to do that. Instrumental and operational definitions could be useful in order to guide scientific research, providing not only theoretical frameworks, but also tools to design experiments and to assess them. But in any case the simplistic dichotomy between realism and conventionalism must be overcome.

\section{Acknowledgments}

I would like to thank Cristian Saborido (UNED) and Alba Amilburu (Universidad del País Vasco) for their valuable comments and suggestions. Jaime Soler is supported by the Spanish Ministry of Science, Innovation and Universities under grant FFI2017-89639-P. 


\section{REFERENCES}

Benner, S. A. 20 io, "Defining life", Astrobiology, 10 (10): 1021.

Benner, S. A.; Ricardo, A.; Carrigan, M. A. 2004, "Is there a common chemical model for life in the universe?", Current opinion in chemical biology, 8 (6): 672-89.

Bich, L.; Green S. 20i 8, "Is Defining Life Pointless? Operational Definitions at the Frontiers of Biology", Synthese, 195 (9): 3919-46.

Bor Luen TAng 2012, "A Minimal or Concise Set of Definition of Life is Not Useful", Journal of Biomolecular Structure and Dynamics, 29 (4): 613-4. DOI: $10.1080 / 073911012010525003$

Boyd, R. I99I, "Realism, anti-realism and the enthusiasm for natural kinds", Philosophical Studies, 61 (1): 127-48.

Boyd, R. I999, "Homeostasis, species, and higher taxa”, R. WiLson (ed.), Species: New interdisciplinary essays, Cambridge: MIT Press, 141-85.

Brigandt, I. 2003, "Species Pluralism Does Not Imply Species Eliminitivism", Philosophy of Science, 70 (Proceedings): 1305-16.

BRIgANDT I. 20 I I, "Natural kinds and concepts: A pragmatist and methodologically naturalistic account”, J. Knowles \& H. Rydenfelt (ed.), Pragmatism, science and naturalism, Berlin: Peter Lang Publishing, 171-96.

Cleland C. E.; Chyba C. F. 2002, "Defining 'life", Origins of Life and Evolution of the biosphere, 32 (4): 387-93.

Cleland, C. E. 20 I 2; 20 i I, "Life without definitions", Synthese, 185 (1): 125-44.

Cleland C. E.; Copley S. D. 2005, "The possibility of alternative microbial life on Earth”, International Journal of Astrobiology, 4 (3-4): 166-73.

Craver, C. F. 2009, "Mechanisms and natural kinds", Philosophical Psychology, 22 (5): 575-94.

Damiano L.; Luisi P. L. 20io, "Towards an Autopoietic Redefinition of Life", Origin of Life and Evolution of Biospheres, 40: 145-9.

DiÉguez, A. 2007, "La relatividad conceptual y el problema de la verdad: Bases para un realismo ontológico moderado", Contrastes. Revista Internacional de Filosofía, 12: 71-91.

Diéguez, A. 2008, “¿Es la vida un género natural? Dificultades para lograr una definicion del concepto de vida", ArtefaCToS, 1: 81-100.

Diéguez, A. 2013, "Life as a homeostatic property cluster", Biological Theory, 7 (2): 180-6.

Dupré, J. I98 I, "Natural kinds and biological taxa”, Philosophical Review, 90: 66-90.

Dupré, J. 1993, Disorders of things: Metaphysical foundations of the disunity of science, Cambridge, MA: Harvard University. 
Dupré, J. I999, “Are whales fish”, D. Medin \& S. Atran (ed.), Folkbiology, MIT Press, 461-76.

EReshefsky, M. 20io, "What's wrong with the new biological essentialism", Philosophy of Science, 77 (5): 674-85.

Ferreira, M.; UMEREZ, J. 20 i 8, "Dealing with the changeable and blurry edges of living things: a modified version of property-cluster kinds", European Journal for Philosophy of Science, 8: 493-518.

Ganti, T. 2003, The Principles of Life, Oxford University Press.

Hacking, I. 2007, "Natural Kinds: Rosy Dawn, Scholastic Twilight", Royal Institute of Philosophy Supplements, 61: 203-39.

Hermida, M. 20i6, "Life on earth is an individual", Theory in Biosciences, 135 (1): 37-44.

Keller, E. F. 2002, Making sense of life: Explaining biological development with models, metaphors, and machines, Cambridge, Mass: Harvard University Press.

Khalidi, M. 20I3, Natural Categories and Human Kinds. Classification in the Natural and Social Sciences, Cambridge: Cambridge University Press.

Lange, M. I996, "Life, 'artificial life' and scientific explanation", Philosophy of Science, 63 (2): 225-44.

Luisi, P. L. I998, "About various definitions of life", Origins of Life and Evolution of the Biosphere, 28: 613-22.

Luisi, P. L. 2006, The Emergence of Life. From Chemical Origins to Synthetic Biology, Cambridge: Cambridge University Press.

Luisi, P. L. 201 5, "Chemistry Constraints on the Origin of Life", Israel Journal of Chemistry, 55 (8)): 906-18. Web

Machery E. 201 2, "Why I Stopped Worrying about the Definition of Life... and Why You Should as Well”, Synthese, 185 (1): 145-64.

Mariscal, C.; Doolittle, W. F. 20 i 8, "Life and life only: a radical alternative to life definitionism", Synthese: 1-15.

Maturana Romesín, H.; Varela, F. J. 2008, De máquinas y seres vivo. Autopoiesis: La organización de lo vivo, Santiago de Chile: Editorial Universitaria [7a ed.].

Moreno, A.; Fernández. J. I997, "Definición de vida y universalización de la biología”, Arbor, 621: 101-12.

Oкаsна, S. 2002, "Darwinian metaphysics: Species and the question of essentialism", Synthese, 131 (2): 191-213.

Pace, N. R. 200I, "The universal nature of biochemistry", Proceedings of the National Academy of Sciences of the United States of America, 98 (3): 805-8. DOI: $10.1073 /$ pnas.98.3.805

Popa, R. 2004, Between Necessity and Probability: Searching for the Definition and Origin of Life, Heldergberg: Springer. 
PopA, R. 201 2, "Merits and Caveats of Using A Vocabulary Approach to Define Life", Biomol Struct Dyn, 29 (4): 607-8.

Putnam, H. I988, Razón, verdad e historia, Madrid: Tecnos.

Razetto-Barry P.; Ramos-Jiliberto R. 201 3, ¿Qué es autopoiesis? Autopoiesis: Un concepto vivo, Santiago de Chile: Editorial Nueva Civilización, 27-57.

Ruiz-Mirazo, K.; Peretó J.; Moreno A. 2004, "A universal definition of life: autonomy and open-ended evolution", Origins of Life and Evolution of the biosphere, 34 (3): 323-46.

SaGan, C. I970, "Life", Encyclopedia Britannica, Chicago, 1083-1083A.

Slater, M. 20I4, "Natural Kindness", The British Journal for the Philosophy of Science, 66: 375-411.

Smith, K. C. 20I6, "Life is hard: countering definitional pessimism concerning the definition of life", International Journal of Astrobiology, 15: 277-89.

Smith, K. 2018, "Life as Adaptive Capacity: Bringing New Life to an Old Debate”, Biological Theory, 13 (2): 76-92.

Tirard, S.; Morange, M.; Lazcano, A. 20io, "The Definition of Life: A brief History of an Elusive Scientific Endeavor", Special Collection of Essays: What is Life? Astrobiology, 10 (10): 1003-9.

Trifonov, E. N. 20II, "Vocabulary of definitions of life suggests a definition", Journal of Biomolecular Structure and Dynamics, 29 (2): 259-66. DOI: $10.1080 / 073911011010524992$

Tsokolov, S. 20го, "A theory of circular organization and negative feedback: defining life in a cybernetic context", Astrobiology, 10 (10): 1031-42. 
